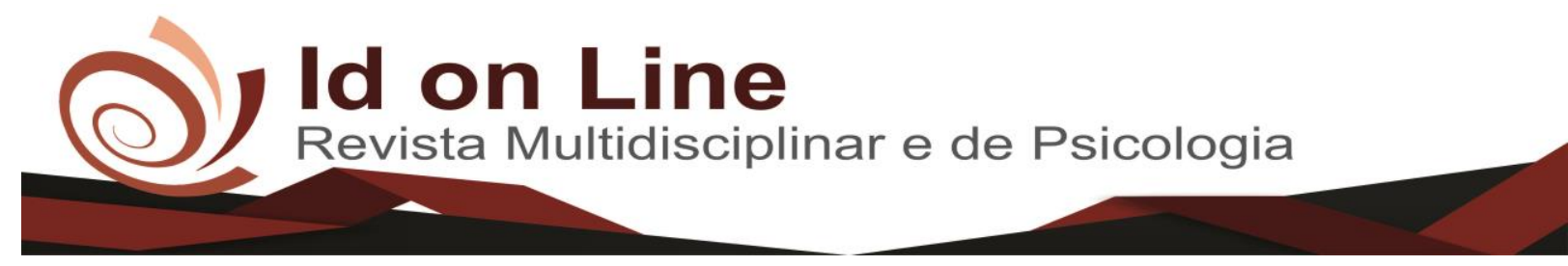

Artigo de Revisão

\title{
Espiritualidade Enquanto Estratégia Subjetiva em Busca de Sentido para a Vida
}

\author{
João Paulo Bezerra de Souza ${ }^{1}$; Thércia Lucena Grangeiro Maranhão² ; Maria das Graças de Carvalho ${ }^{3}$; \\ Katissa Galgânia Feitosa Coutinho Rodrigues ${ }^{4}$
}

\begin{abstract}
Resumo: O presente artigo tem como pergunta norteadora: como a espiritualidade ampara o sofrimento do sujeito, dando sentido a sua vida? Teve-se como objetivo geral analisar como a espiritualidade favorece a ressignificação do eu dando amparo e sentido a sua vida. Pretende-se também identificar se a religiosidade/espiritualidade, podem contribuir a qualidade de vida em termos gerais do sujeito. Deve-se ainda, estudar a associação entre a espiritualidade enquanto atividade complementar na promoção da saúde das pessoas. Considera-se necessário, analisar se a espiritualidade com o intuito de promover a redução do sofrimento diante o desamparo fundamental do homem. A escolha do tema ocorreu a partir do interesse pessoal em conhecer e compreender como a espiritualidade ampara o sujeito em sua busca pelo sentido da vida. Ao final do trabalho percebeu-se a relevância do tema e a existência de poucos trabalhos com esta relação validados pela psicologia, como sendo um assunto que deve ser mais discutido.
\end{abstract}

Palavras chaves: Psicologia; Religiosidade; Espiritualidade.

\section{Spirituality as a Subjective Strategy in the Search for Life Meaning}

\begin{abstract}
The present article has as guiding question: how does spirituality support the suffering of the subject, giving meaning to his life? The general objective was to analyze how spirituality favors the resignification of the self by giving support and meaning to its life. It is also intended to identify whether religiosity/spirituality can contibute the quality of life in general terms of the subject. It is also necessary to study the association between spirituality as a complementary activity in the attention of the psychic health. It is considered necessary to analyze whether spirituality promotes the reduction of suffering in the face of the fundamental helplessness of man. The choice of theme was based on personal interest in knowing and understanding how spirituality supports the subject in his search for the meaning of life. At the end of the work the relevance of the subject and the existence of few works with this relation validated by psychology were perceived as being a subject that should be more discussed.
\end{abstract}

Keywords: Psychology; Religiosity; Spirituality.

\footnotetext{
${ }^{1}$ Graduando do curso de Psicologia pela UNILEÃO-Centro Universitário. E-mail: joaopauloseguros@ymail.com

${ }^{2}$ Psicóloga. Professora do Centro Universitário Dr. Leão Sampaio- UNILEÂO.Especialista em Gestão do Trabalho e da Educação na Saúde pela Escola de Saúde Pública do Estado do Ceará. Pós-Graduanda, do curso de Mestrado em Ciências da Saúde na Faculdade de Medicina do ABC-FMABC. E-mail: thercia@leaosampaio.edu.br

3 Professora - Mestra em Ciências da Educação pela Universidade Lusófona de Humanidades e Tecnologias - ULHT- Lisboa/Portugal; Possui graduação em História pela Faculdade de Formação de Professores de Araripina-PE - FAFOPA(1990). Especialização em: Metodologia do Ensino Superior(AEDA); Psicopedagogia em Educação (Leão Sampaio) ; Historia e sociologia (URCA)Educação contextualizada no semiárido (UESPI); Politicas Educativas e Docência do Ensino Superior(AEDA); Atualmente: Secretaria Adjunta da secretaria municipal de educação da cidade de Simões - PI; Professora do Centro de Educação Municipal de simões-PI. Contato: grace.artur@hotmail.com;

${ }^{4}$ Graduada em Biblioteconomia pela Universidade Federal do Ceará/Campus do Cariri (UFC), Especialista em Docência do Ensino Superior pela Faculdade Integrada de Patos(FIP). Graduada em Psicologia pelo Centro Universitário Dr. Leão Sampaio (UNILEÃO). Especialista em Psicologia Aplicada a Educação pela Universidade Regional do Cariri (URCA). katissagalgania@ yahoo.com.br.
} 


\section{Introdução}

As temáticas da religião e da espiritualidade, sempre foram alvo de interesse do homem em diversas épocas e culturas, mas somente na contemporaneidade a ciência levantou o interesse de investigar conhecer mais acerca dos temas (HENNING \& MORÉ, 2009).

Para dar início a este trabalho se faz necessário conceituar o que é religião e espiritualidade. Dentre os vários conceitos estabelecidos, de diversos autores, elegemos os conceito de Koenig (2012), que compreende religião como um sistema organizado de crenças, práticas, rituais e símbolos projetados para auxiliar a proximidade do indivíduo com o sagrado e/ou transcendente, referindo-se à espiritualidade como uma busca pessoal de respostas sobre o significado da vida; e também o William James (1991), que toma a religião como os sentimentos, atos e experiências de indivíduos em sua relação com o divino.

Freud, no entanto, em sua clássica obra O futuro de uma ilusão, de 1927, entendia que a prática religiosa era decorrente de uma neurose obsessiva universal (FREUD, 1996). Ainda para Freud, tanto para o neurótico como para a pessoa religiosa a ritualística imposta a eles os salvariam ou os livrariam de suas angústias diante a vida (grifos meus).

Freud afirma que a religião é uma ilusão criada, um autoengano da psique, onde esta tem o intuito de sanar o desamparo infantil e Deus estaria numa grande e eterna função paterna (FREUD, 1996).

Todavia, com estudos mais recentes da psicanálise, vindo de encontro ao que Freud considerara, Winnicott (1988) nos traz que todo ser humano carrega consigo uma tendência inata ao desenvolvimento, direcionada à realização pessoal, havendo a necessidade de um meio ambiente humano, capaz de viabilizar a atualização destas possibilidades. Neste sentido a ilusão torna-se uma formadora de singularidade, ressignificando, desta maneira, as demandas do meio em que está inserido, sendo esta uma característica inata aos seres humanos.

Diante do exposto acima, surge o seguinte questionamento: como a espiritualidade ampara o sofrimento do sujeito, dando sentido a sua vida?

Afim de responder à pergunta, tem-se como objetivo geral analisar como a espiritualidade favorece a ressignificação do eu, dando amparo e sentido à sua vida. Pretendese também identificar se a religiosidade/espiritualidade, podem melhorar a qualidade de vida 
em termos gerais do sujeito. Deve-se ainda, estudar a associação entre a espiritualidade enquanto atividade complementar na promoção da saúde das pessoas. Considera-se necessário analisar se a espiritualidade pode promover a redução do sofrimento diante do desamparo fundamental do homem.

A escolha do tema pelo pesquisador, justifica-se, a partir do interesse em conhecer e compreender como a espiritualidade ampara o sujeito em sua busca pelo sentido da vida.

Partiu-se da experiência pessoal de finitude da vida devido a um acidente e o processo de recuperação, onde a espiritualidade teve um papel de fundamental importância na recuperação da saúde, promovendo um sentimento de amparo otimismo, esperança e um novo olhar e posicionamento diante da vida.

O trabalho apresenta sua relevância à comunidade acadêmica na medida em que faz um alerta sobre a necessidade de outros estudos que comprovem a contribuição da espiritualidade no tratamento psicoterápico, enquanto uma técnica complementar.

O sujeito contemporâneo e demandado por inúmeras exigências que estão comprometendo sua saúde, dessa maneira, há a necessidade de buscar novas formas de intervenções psicoterápicas para a melhoria da qualidade de vida e a ressignificação do sujeito.

Trata-se de uma revisão de literatura a partir de textos, livros e artigos científicos sobre o tema; sendo esta uma investigação cientifica que consiste em levantar, reunir, avaliar criticamente e sintetizar resultados. A revisão de literatura por si só é um processo que busca fazer uma análise e descrição sobre um determinado conhecimento disponível na bibliografia, partindo de uma pergunta de partida (MATTOS, 2015).

Foi realizada uma pesquisa de artigos nas bases de dados: BDTD; PEPSIC; Scielo, BVS e Pubmed, publicadas sobre temas e também em livros considerados clássicos da literatura específica para tentar adquirir subsidio necessário à discussão.

O resultado do trabalho mostra-se como uma nova possibilidade de refletir conceitos sobre a espiritualidade pode auxiliar no processo psicoterápico como uma complementaridade, não tendo a pretensão de esgotar os estudos do tema, mas propor um novo olhar para antigas questões. 


\section{Metodologia}

\section{Fluxograma do estudo}

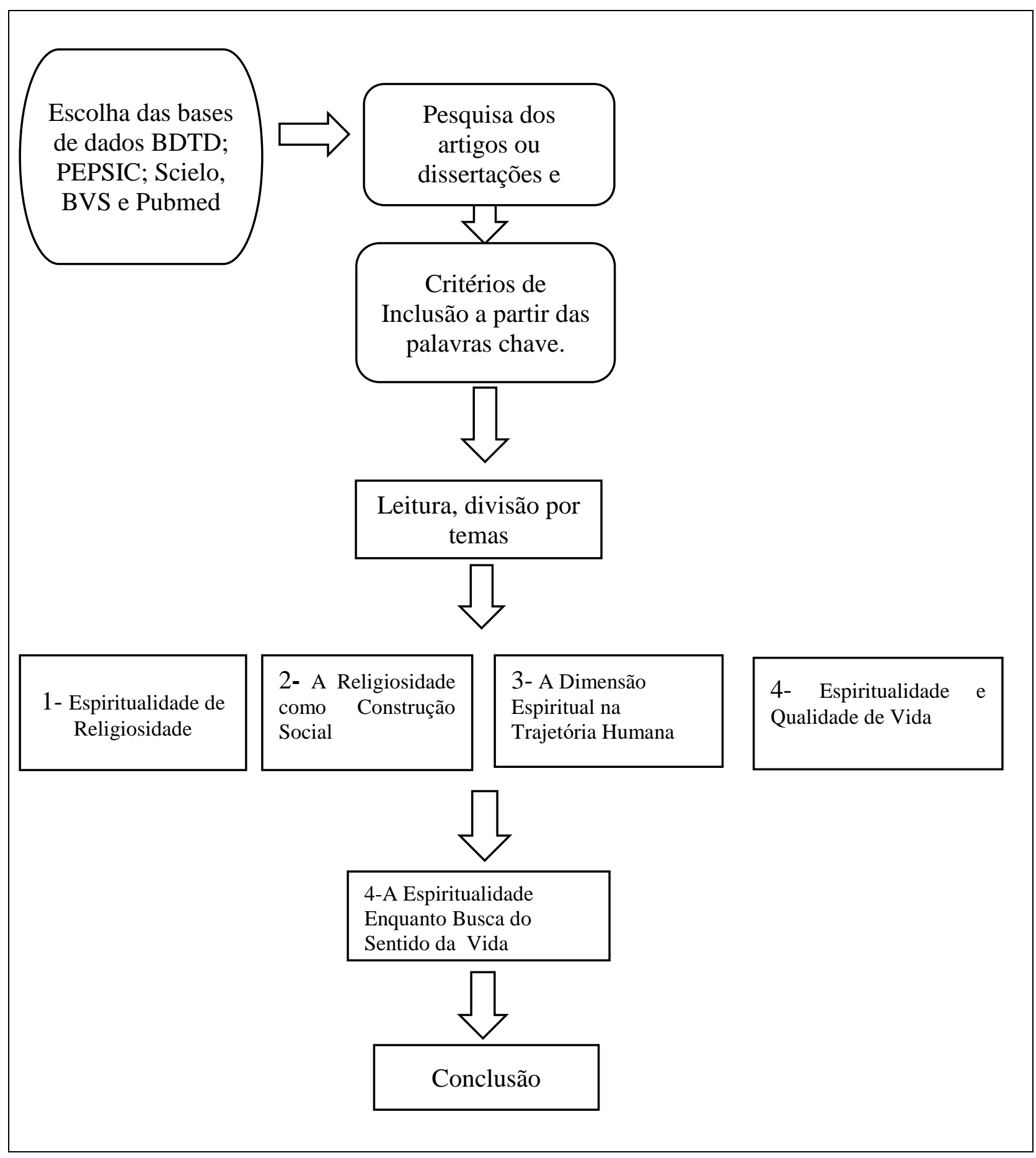


O presente trabalho propõe uma revisão de literatura de artigos científicos e dissertações de mestrado e livros sobre o tema. A revisão de literatura ou pesquisa bibliográfica tem a finalidade de identificar produções sobre o tema na literatura científica e possíveis relações entre variáveis vinculadas ao tema a partir da perspectiva dos autores, com a finalidade de conduzir a uma análise crítica da produção científica anteriormente elaborada (GIL, 2010).

No início para o levantamento de dados foi realizada uma revisão bibliográfica de maneira sistemática nas principais bases de dados de pesquisa científica, como BDTD; PEPSIC; Scielo, BVS e Pubmed, baseados em livros, publicações acadêmicas, internet e artigos de revistas científicas sobre o tema a ser discutido. Neste momento foram utilizados os seguintes descritores: psicologia, religiosidade, espiritualidade e qualidade de vida.

Para Oliveira (2011), a pesquisa bibliográfica procura explicar o problema a partir de referenciais teóricos já publicados em documentos. Busca conhecer e analisar as condições culturais ou científicas do passado sobre determinado assunto, tema ou problema.

\section{Diferenciando Espiritualidade de Religiosidade}

O termo religião comporta inúmeras e diferentes formas de manifestação da religiosidade. Por isso, esse termo específico significa um coletivo, onde não se encontra uma essência única (ARAKI, 2003). Neste trabalho, tomaremos como norte, pela relevância do autor na temática, a concepção de William James (1991) de religião, em sua clássica e renomada obra, As variedades da experiência religiosa: “(...) os sentimentos, atos e experiências de indivíduos em sua solidão, na medida em que se sintam relacionados com o que quer que possam considerar o divino" (p. 25).

De acordo com Pessini e Bertanchini (2006) a etimologia da palavra espiritualidade significa sopro da vida, encontrar um sentido. A espiritualidade, é a busca pela transcendência, que independe de religião e seus dogmas, é um contato subjetivo com o sagrado. 
A espiritualidade é também a busca de um sentido transcendente, a busca de um sentido mais amplo, dando para aquele que procura o sagrado, o divino, um sentido ao seu provir.

Frankl (1973) mostra a importância da busca do sentindo, em tempos, onde a o vazio existencial e apatia se tornaram tão presente e no nosso cotidiano. Ainda para o autor, a apatia é a forma mais salutar de proteger a alma do temor, das angustias. Estimular a busca do ser e responsabilizar-se por suas escolhas. Estas buscas são alicerçadas pela espiritualidade, a busca por um sentido maior e mais amplo da vida, a busca pelo sentido subjetivo cada um, dando ao que busca o sentido da vida e a resposta à sua procura, e não uma confirmação genérica. Frankl postula ainda que não se deve dar um sentido à vida e sim encontrar esse sentido, para o qual a espiritualidade é um caminho assertivo.

Segundo Frankl, a vida não perde o sentido com a finitude, muito pelo contrário: o fenecer diante da vida dá ao homem um sentido diante dela, que pela brevidade pensemos e nos responsabilizemos por nossas escolhas.

Safra (1999), retomando algumas das ideias de Winicott, se refere às experiências de encantamento, de júbilo que podem nos remeter ao sagrado. Nem sempre estão ligadas às religiões tradicionais, podendo surgir muito antes de se ter uma religião definida. Segundo o autor, estas experiências poderão posteriormente ser vinculadas a uma religião particular, ou ligadas ao espírito religioso, no sentido do religare, em conexão com a transcendência.

Religião segundo Koenig (2012) é um sistema organizado de crenças, práticas, rituais e símbolos projetados para auxiliar a proximidade do indivíduo com o sagrado e/ou transcendente, e espiritualidade como uma busca pessoal de respostas sobre o significado da vida e o relacionamento com o sagrado e/ou transcendente.

Ainda nesta perspectiva, Dalgalarrondo (2008) afirma que a religião, vista como entidade social ou psicológica abstrata, revela o que lhe é mais essencial e original: as experiências íntimas, pessoais, altamente emocionais da fé religiosa.

Segundo Amattuzzi (1999), é também um campo de experiências, campo de indagações sobre a sua estória de vida, abrindo-se para novas possibilidades através do transcender, elaborando consciência do eu no processo do provir. O que se busca com a religião é a busca com além vida, o mistério, onde o a religiosidade é portal de contato de sua individualidade e o sagrado. 
A religiosidade para Dalgalarrondo (2008) parece ser fundamental naqueles momentos de maior impacto para os indivíduos, como perda de pessoas próximas, doença grave, incapacitação e morte. $\mathrm{O}$ autor apresenta este como elemento constitutivo da subjetividade e doador de significado ao sofrimento, defendendo que ela deva ser considerada um objeto privilegiado na interlocução com a promoção de saúde, indicando caminhos para uma vida mais saudável.

Percebe-se que apesar de diferentes, os conceitos de religiosidade e espiritualidade conseguem alcançar o objetivo de responder os questionamentos subjetivos do homem, diminuindo, em alguns casos, sua angústia existencial. Para ilustrar melhor de que maneira isso se dá, será trazido a seguir o exemplo da cidade de Juazeiro do Norte, no interior do estado Ceará, onde o alcance e a importância da religiosidade se mostram de forma relevante.

\section{Religiosidade Como Construção Social em Juazeiro do Norte}

Percebe-se que as pessoas, os sujeitos, possuem características singulares, mas que, no entanto, apresentam traços da cultura e da organização social da qual fazem parte. A relações sociais moldam a crença que define o sujeito e seu papel social, que acabam moldando o que se é, ou melhor, o que se acredita ser. Neste sentido, ampliando-se esta compreensão, pode-se questionar se o que ele acredita sobre si mesmo perpassa pelo que a cultura vigente impõe e determina.

Juazeiro do Norte é uma cidade média, a maior cidade do interior do estado do Ceará. Seu crescimento se deu por causa do fenômeno religioso encabeçado pelo Padre Cícero, tido como personagem emblemático e mais importante da história dessa cidade. Em um misto de sagrado e profano o comércio cresce nas romarias. A economia se desenvolve de forma diversificada entre camelôs, ambulantes, lojistas e feirantes e desperta interesse de empreendedores de outras regiões do Brasil (ANDRELINO, 2013).

A cidade enche-se de pessoas de muitos lugares, entre rituais e expressões de fé, onde está o olhar para outros aspectos sociais que estão presentes e subentendidos nesses espaços como a institucionalização da fé pela religião. Observa-se que a religião tem para a cidade 
grande finalidade comercial e econômica, sendo um negócio rentável que movimenta gerações de devotos em um encontro de gerações em torno da fé religiosa.

O encontro de gerações acontece em todos os momentos do evento religioso, a cantiga religiosa é entoada por alguém designado pela família que tenha um histórico de devoção e fé ao sagrado, portanto alguém de destaque para os membros (FERNANDES, 2005).

É interessante constatar que a religiosidade cristã professada na cidade de Juazeiro do Norte, que tem em sua maioria populacional adeptos do catolicismo, é um fenômeno passados de pai para filho: os ancestrais da família inserem os membros mais jovens para que estes representem, sigam e também passem às gerações posteriores a tradição religiosa. Tendo, nesse contexto, o sagrado como a realidade propriamente dita e vivida (ELIADE, 2008), compreende-se enquanto experiência de fé, experiência em conjunto.

\section{A Dimensão Espiritual Presente na Trajetória da Condição Humana}

A ligação do homem com a dimensão espiritual sempre esteve presente na trajetória histórica da humanidade. A religião sempre ocupou espaços de destaque como meio de encontrar respostas para perguntas existenciais. O fato é que a questão espiritual sempre esteve muito entrelaçada com as vidas, experiências, frustrações e esperanças do ser humano (HOWARD, 2002).

Pesquisadores como Ashforth \& Pratt (2003) e Howard (2002), espiritualidade é uma realidade exclusivamente individual e pessoal, assim como um contraponto inclusiva e universal. Assim, o indivíduo a expressa pela maneira como interage com o mundo e pela habilidade com que extrai recursos internos, tais como verdade e crenças subjetivas, sentimento como amor, sentido de serviço ou utilidade social, e totalidade.

Percebe-se, portanto, que a espiritualidade é tão importante quanto outras coisas essenciais à nossa existência, como a necessidade de suprir a fome, a sede, o afeto, e assim por diante, através dos fenômenos da fé, esperança e confiança em um poder superior (HOWARD, 2002).

King e cols. (1999) comentam a respeito da reconciliação dos indivíduos consigo mesmos retratando um movimento internalizante, introspectivo, o que os leva a desabrochar suas capacidades e, por conseguinte pessoais, e a contribuírem de maneira significativa para a 
vida coletiva em comunidade, além disso, envolve a autoconsciência, a harmonia e o desenvolvimento do self e a busca de unidade entre seus aspectos internos e com os outros com os outros.

\section{Espiritualidade e Qualidade de Vida}

A Organização Mundial de Saúde - OMS, compreende qualidade de vida enquanto fator subjetivo, interno, pois está diretamente ligado a percepção das condições físicas, emocional e social, tendo relação aos aspectos temporais, culturais e sociais (GONÇALVES \& VILARTA, 2004).

Baseando-se nas principais teorias e no entendimento empírico, compreende-se a qualidade de vida como fator que favorece a felicidade, como algo que depende do plano de vida de cada indivíduo, que é expresso de maneira individual e muito subjetivo. Portanto, cabe compreender que a espiritualidade contribui de forma incisiva para a ideia de qualidade de vida (BRAMANTE, 2004).

Ter uma boa qualidade de vida implica em considerar as dimensões físicas, psicológicas, social e espiritual, devendo ser observado em qualquer fase do desenvolvimento humano da pessoa humana (NERI \& FREIRE, 2000).

A construção dessa qualidade é uma variável que resulta do desenvolvimento pessoal e coletivo, embora seja dependente de diversos fatores que irão determinar a capacidade de produzir a felicidade e uma vida saudável (BRAMANTE, 2004).

A ideia de ter boa qualidade de vida está intrinsecamente relacionada a interpretação pessoal de quanto o indivíduo realizou daquilo que considera importante, a distância entre o idealizado e o realizado e a satisfação com o que foi possível concretizar até o momento (PASCHOAL, 2004).

Nesse sentido, se compreende que a longevidade envolve a geriatria, medicamentos, alimentos, drogas para retardar o envelhecimento, exercícios físicos e lazer. No enfoque da função social o que se discute sobre o papel do idoso em uma sociedade produtiva, de estar e sentir-se inserido, assim significa que ele está produzindo, bem como ter objetivo de vida (PARK, 2003). 
No âmbito da psicologia algumas condições são expressas, nas quais é possível ocorrer a preservação do potencial para o comportamento e desenvolvimento. Em algumas áreas do desenvolvimento intelectual, a alta competência para desenvolver atividades práticas e conviver com problemas existenciais complexos, de acordo e dependentes do acúmulo de experiência de vida (NERI, 2002).

Alguns fatores são indicados para uma vida satisfatória como: boa saúde, contatos sociais, rede de amigos, presença de pessoas que se tornam confidentes, renda satisfatória, educação, estado civil, atividade, religião, atitude positiva perante a velhice, lazer, boas relações com a família, participação voluntária em trabalhos na comunidade em que está inserida. Nesse sentido, a avaliação do bem-estar psicológico está intimamente associada à avaliação de solidão, que consequentemente pode ser influenciada por fatores como a história de vida, personalidade e valores pessoais (CAPITANINI \& NERI, 2004).

Percebe-se, portanto, que a qualidade de vida está associada também ao significado transcendente que o sujeito atribui a sua existência a seus arranjos internos, subjetivos, psicológicos sobre afeto, cuidado, ou em sua ausência solidão e desamparo.

\section{A Espiritualidade Enquanto Busca do Sentido da Vida}

A importância de se trabalhar com a busca pelo sentido da vida, numa época em que o vazio existencial e a apatia estão tão presentes. Segundo o autor, a apatia pode ser uma forma de lidar com o temor, protegendo-se a alma, portanto, estimula-se a consciência do ser, da sua responsabilidade e da expressão do que é mais humano no ser. Esta busca mais profunda pode estar ancorada na espiritualidade (FRANKL ,1973; KOVÁCS, 2007).

Segundo o autor acima o que de fato impulsiona o homem a seguir seu caminho na vida, não é nem a vontade de poder (como aponta Adler), nem a vontade de prazer (como em Freud), mas sim o que Frankl chama de vontade de sentido (MOREIRA \& HOLANDA, 2010). A transcendência aparece como fator que impulsiona à vida, a esperança a continuidade e a completude.

O autor postula que o ser humano está inserido na sua história e é responsável pelo seu destino. Responsabilidade é entendida como a possibilidade de responder, fazer escolhas, e, neste sentido, construir a sua existência. Segundo o autor, nada acontece ao acaso, há um 
sentido para tudo, mesmo que num primeiro momento possa não estar tão claro. A busca pelo sentido é subjetiva, própria de cada um, por isto não há como buscar um sentido genérico (FRANKL, 1973; KOVÁCS, 2007). O sentido tem um caráter objetivo de exigência e está no mundo, não no sujeito que o experiencia (MOREIRA \& HOLANDA,2010), portanto, é algo possível a qualquer pessoa que queira apropriar-se deste.

Afirma Frankl: a questão não é dar sentido, e sim encontrá-lo, não pode ser inventado, deve ser descoberto. Não há situações sem saída, sempre há uma que será a escolhida; não dar respostas já é uma resposta. Cabe ao terapeuta apontar que a situação não é sem saída em si, embora possa ser percebida como tal. O sentido da vida se dá, também, pela percepção da finitude, pela morte. Muitas pessoas pensam de maneira errônea que a morte é o que provoca a falta de sentido, mas é justamente nos sabermos finitos, que permite que vejamos o sentido da nossa existência (FRANKL ,1973; KOVÁCS, 2007).

Ao falar de sentido, estamos fazendo referência ao significado, à coerência, à busca de propósito e finalidade. Frankl nos expressa como o homem que perdeu o sentido cai em um vazio existencial e sofre; esta frustração existencial pode desembocar em uma sintomatologia neurótica que, como já mencionamos (PEREZ, 1997; MOREIRA \& HOLANDA, 2010).

Portanto, perceber que o sentido da vida seria para Frankl é compreender que o homem não é o seu corpo, suas pulsões organizadas, racionalizadas ou apenas sentimentos e ideias; mas um todo de todos estes atores, ressignificando através de sua dimensão transcendente e ampliando conceitos importantes para o comportamento humano que estavam até então marginalizados, do que seria o conhecimento científico.

\section{Conclusões}

$\mathrm{Na}$ trajetória da pesquisa percebi que pontes estavam sendo feitas em um campo onde não havia essa abertura, mesmo a bioestatística indicando que não havia probabilidades de se reorganizar em sua plenitude. Porém, de maneira vinculada a minha busca pessoal, o contato com o subjetivo com a espiritualidade mostrou possibilidade de reverter o que era irreversível, produzindo dessa maneira uma nova perspectiva diante da vida, percebo que foi para além de apenas um trabalho de conclusão de curso, marcando o início de uma nova história. 
A pesquisa conseguiu verificar a importância da espiritualidade para a melhoria da qualidade de vida das pessoas, minimização de fatores estressores, estímulo a ressignificação, amparo necessário, em alguns casos, à busca do sentido da existência.

O referido trabalho discorreu sobre o poder da ressignificação do sentido da vida a fim de minimizar situações estressoras através da espiritualidade, contato este, que promovendo a fé e esperança.

A pesquisa conclui que estes temas abordados por perspectivas diferentes acabam por evidenciar a necessidade de compreensão mais ampla partindo do bem-estar do cliente como fator de mobilização e compreensão entre as diversas abordagens que marcam a história da psicologia enquanto ciência recente que ainda necessita de novas considerações e aprofundamentos.

\section{Referências}

AMATUZZI, M. M. Desenvolvimento religioso: uma hipótese descritiva. In: MASSIMI, M. \& MAHFOUD, M. (Orgs.). Diante do mistério: psicologia e senso religioso. São Paulo: Loyola; 1999. p.123-40.

ANDRELINO, Paulo César de Lima. Religião e Mercado em Juazeiro do Norte: expressão do Sagrado e do consume religioso na terra do meu "Padim". Dissertação (Mestrado) - Universidade Católica de Pernambuco, Mestrado em Ciências da Religião, Recife, 2013.

ARAKI, Mauro Junji. Religião e Pragmatismo em William James. Universidade Federal de São Carlos, Departamento de Psicologia. Monografia de Bacharelado, 2003

ASHFORTH, B. E. \& PRATT, M. G. Institutionalized spirituality: an oxymoron? In: GIACA- LONE, R. A.; JURKIEWICZ, C. L. (Ed.). Handbook of workplace spirituality and organizational performance. New York: M. E. Sharpe, 2003. p. 93-107.

BRAMANTE, A. C. Qualidade de vida e lazer. Em Gonçalves, A. \& Vilarta (Org). Qualidade de vida e atividade física: explorando teorias e práticas. Barueri, SP: Manole, 2004.

CAPITANINI, M. E. S \& NERI, A. L. Sentimentos de solidão, bem-estar subjetivo e relações sociais em mulheres idosas vivendo sozinhas. In: Neri, A. L. \& Yassuda, M. S. (Org.) Velhice bem sucedida: Aspectos afetivos e cognitivos. Campinas, SP: Papirus, 2004.

DAlgalarRondo, P. Religião, Psicopatologia \& Saúde Mental. Porto Alegre: Artmed; 2008. 
FERNANDES, Glauco Vieira. O sagrado coração enquanto símbolo tradicional. In: Tendências: caderno de ciências sociais. Crato: Departamento de Ciências Sociais da Universidade Regional do Cariri (URCA), 2005.

FRANKL, V. Psicoterapia e sentido da vida. São Paulo: Quadrante; 1973.

FREUD, Sigmund [1927]. O futuro de uma ilusão. In: Edição Standard Brasileira das Obras Completas de Sigmund Freud, vol. XXI. Rio de Janeiro: Imago, 1996.

JAMES, William. As Variedades da Experiência Religiosa. São Paulo: Cultrix, 1991.

GIL, Antônio Carlos. Como elaborar projeto científico. São Paulo: Atlas, 2010.

GONÇALVES, Aguinaldo \& VILARTA, Roberto Qualidade de Vida: identidades e indicadores. In: GONÇALVES, Aguinaldo e VILARTA, Roberto (Orgs.). Qualidade de Vida e atividade física: explorando teorias e práticas. Barueri: Manole, 2004, p.03-25.

HENNING, Martha Caroline \& MORÉ, Carmen L. O. O. Religião e Psicologia: análise das interfaces temáticas. In: REVER: Revista de Estudos da Religião dezembro / 2009 / pp. 84-114.

MOREIRA, Neir \& HOLANDA, Brasil Adriano. Logoterapia e o sentido do sofrimento: convergências nas dimensões espiritual e religiosa. In: Psico-USF, v. 15, n. 3, p. 345-356, set./dez. 2010345.

HOWARD, Sue. A spiritual perspective on learning in the workplace. In: Journal of Managerial Psychology. Vol. 17, No. 3, p. 230-242, 2002.

KING, S.; BIBERMAN, J.; ROBBINS, L.; NICOL, D. M. Integrating spirituality into management education in academia and organizations: origins, a conceptual framework, and current practices. In: BIBERMAN, J.; WHITTY, M. D. (Ed.). Work and spirit: a reader of new spiritual paradigms for organizations. Chicago: University of Scranton Press, 2000. p. 281-293.

KOENIG, H. G. Medicina, religião e saúde: o encontro da ciência e da espiritualidade. Tradução: Iuri Abreu. Porto Alegre, RS: L\&PM. 2012.

KOVÁCS, Maria Júlia. Espiritualidade e psicologia: cuidados compartilhados. Spirituality and psychology - shared care. In: Espiritualidad y psicología - cuidados compartidos. O MUNDO DA SAÚDE São Paulo: 2007: abr/jun 31(2):246-255 2.

MATTOS, Paulo de Carvalho. Tipos de revisão de literatura. Disponível em: <http://www.fca.unesp.br/Home/Biblioteca/tipos-de-evisao-de-literatura.pdf> Acesso em: 15/05/2017.

NERI, A. L. \& FREIRE, S. A. (Orgs.). E por falar em boa velhice. Campinas: Papirus, 2000.

NERI, A. L. \& SOMMERHALDER, C. As várias faces do cuidado e do bem-estar do cuidador. In: Neri, A. L. (Org.). Cuidar de idosos no contexto da família: questões psicológicas e sociais. Campinas, SP: Editora Alínea, 2002.

ELIADE, Mircea. O sagrado e o profano: a essência das religiões. São Paulo: Martins Fontes, 2008.

OLIVEIRA, Maxwell Ferreira de. Metodologia científica: um manual para a realização de pesquisas em Administração / Maxwell Ferreira de Oliveira. -- Catalão: UFG, 2011. 
PARK, M. B. O ciclo da vida representado nas páginas dos almanaques de farmácia brasileira. In: Simson, O. R. M. V., \& NERI, A. L.; CACHIONI, M. (Orgs.). As múltiplas faces da velhice no Brasil. Campinas, SP: Papirus, 2003.

PASCHOAL, S. M. C. Avaliação da qualidade de vida. Mesa redonda apresentada no XIV Congresso Nacional de Geriatria e Gerontologia. Salvador, Bahia: 2004.

PEREZ, D. Z. Perdida de sentido y neurosis existencial. In: Revista Cubana de Psicología, 14 (1), 65-69.

PESSINI, L. \& BERTANCHINI, L. O que entender por cuidados paliativos. São Paulo: São Camilo, Loyola; 2006.

SAFRA, G. Sacralidade e fenômenos transicionais: Uma visão winnicottiana. In: MASSIMI, M. \& MAHFOUD, M. (Orgs.). Diante do mistério: psicologia e senso religioso. São Paulo: Loyola; 1999. p.173-75.

WINNICOTT, D. W. Natureza humana. Rio de Janeiro: Imago, 1988.

\section{Como citar este artigo (Formato ABNT):}

SOUZA, João Paulo B. de; MARANHÃO, Thércia L. G.; CARVALHO, Maria das Graças de; RODRIGUES, Katissa G.F.C. Espiritualidade Enquanto Estratégia Subjetiva em Busca de Sentido para a Vida.. Id on Line Revista Multidisciplinar e de Psicologia, 2018, vol.12, n.39, p.505-518. ISSN: 1981-1179.

Recebido: 09.01.2018

Aceito: 10.01 .2018 